\title{
SOME HYDROLOGICAL ASPECTS OF A NATURAL FOREST IN THE MID- COUNTRY INTERMEDIATE ZONE OF SRI LANKA
}

\author{
H.B. Nayakekorala1 and C.M. Madduma Bandara ${ }^{2}$ \\ ${ }^{1}$ Natural Resources Management Centre, Department of Agriculture, Peradeniya \\ 'Department of Geography, University of Peradeniya
}

\begin{abstract}
Total and net rainfall were measured by rain gauges in the open and under the canopy, records from a station $5 \mathrm{~km}$ away were also used. Infiltration was measured by a double ring infiltrometer. Transpiration was estimated from changes in soll-moisture storage, as measured by the neutron probe method. Provision was made to measure surface runoff, but there was none; infiltration rates were well above maximum rainfall intensity. Although some of the data are not complete, it is concluded that the tree vegetation loses relatively small amount of water by interception and transpiration in the dry season, for the reason that the roots have limited access to water.
\end{abstract}

\section{Introduction}

Forests cover considerable areas of many reservoir catchments in Sri Lanka. Under the present watershed management projects, reforestation programmes are given high priority, in order to achieve some specific objectives which include the rehabilitation of degraded lands. prevention of sedimentation of reservoirs, and timber production. These programmes can have important hydrological consequences, and they need to be evaluated on their relative advantages and disadvantages.

The effect of tree cover on water yicld is controversial (Madduma Bandara, 1992). Public opinion holds that frequent droughts, low dry-weather flows in rivers and streams, the lowering of ground-water tables, and frequent floods are caused by the deforestation of the watersheds. However, research findings do not necessarily support these views. Some research results have indicated that deliberate reduction of vegetative cover caused no reduction in water yields (Bosch \& Hewlett-1982), logging of trees increased the height of the ground water table (Gilmour 1977), and in the dry zone of Sri Lanka, chena land contributed more than forest to ground water from the rainfall (Munasinghe \& Somasiri 1992). It must be noted that these experiments were carried out under controlled conditions and that generalization of the conclusions may be hazardous.

Hydrologists in Sri Lanka have not been able either to prove or disprove public opinion on the adverse effects of deforestation, because some of the fundamental hydrological processes 


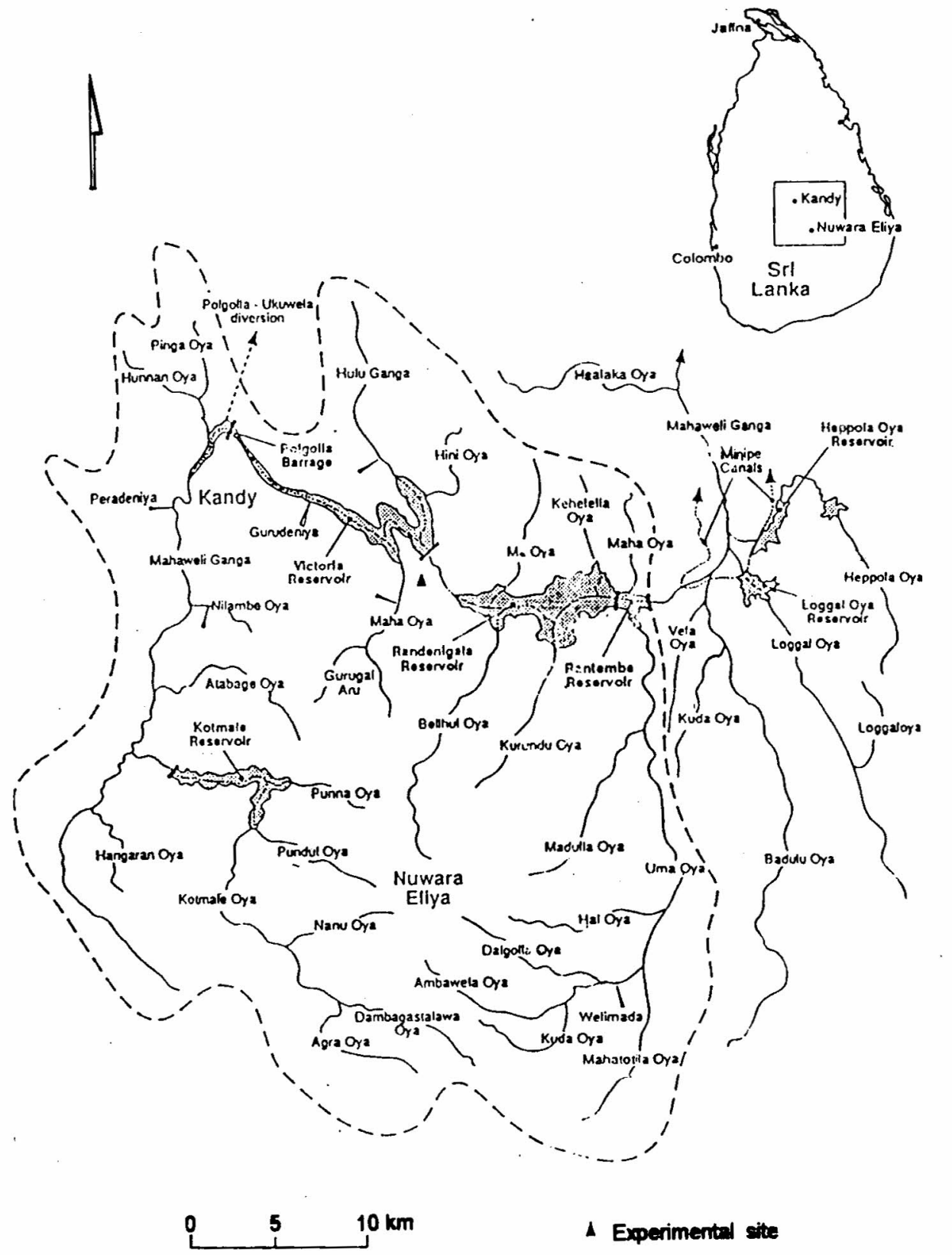

Figure 1: Location map of the experimental site 
on different land-use types are not well understood. A proper understanding of processes such as evapotranspiration. runoff and percolation, and their quantification under different land uses, are basic requirements for characterizing watershed conditions, for prioritizing management options, and for identify indicators that will predict stream flow following land use changes.

A research project is under way to study the hydrological processes under different land-use systems in the mid-country intermediate zone, in order to gather some basic data. This paper discusses the results of an one experiment of this project, which studied soil-water dynamics, water losses and infiltration rates in a natural forest.

\section{Methodology}

A block of natural forest at Malulla in the Hanguranketha Secretariat Division $\left(7.12^{\circ} \mathrm{N}\right.$, $80.48^{\circ} \mathrm{E}$ ) was selected for the study (Fig. 1). A plot of $507 \mathrm{~m}^{2}$ was isolated by an earth bund. A runoff-collecting tank system was constructed at the lower end of the plot (Fig. 2). Three aluminium access tubes were installed at at random positions in the plot, down to bed rock $(150 \mathrm{~cm})$, to measure soil-water content with a neutron moisture probe Three rain gauges were installed at random positions in the plot. to measure throughfall. Another rain galuge was installed in an open space about $100 \mathrm{~m}$ away, outside the forest, to measure direct rainfall. Three sets of tensiometers were installed to monitor soil-water potential in the plot. at depths of 120 and $150 \mathrm{~cm}$.

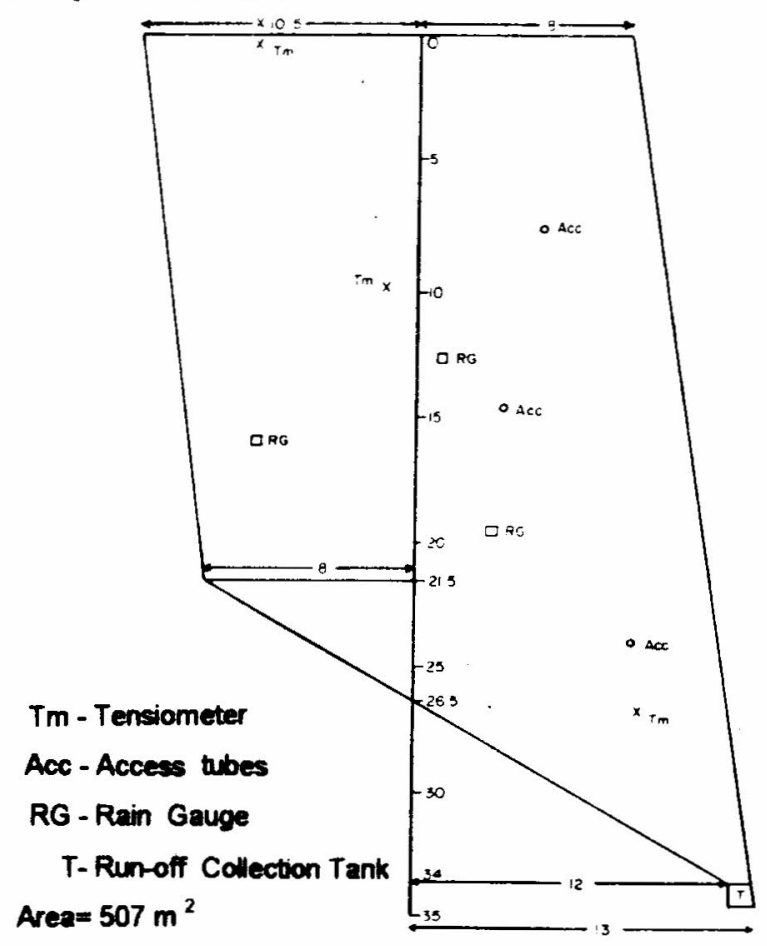

Figure 2: Plan of the experimental plot 
A neutron moisture probe was calibrated for the site, and readings were obtained at regular intervals. An attempt was made to estimate the water loss by forest vegetation, by using the following water balance equation:

where

$$
L=R F-R O-P-S
$$
interception)

$\mathrm{L}=$ water loss from the vegetation (which includes both evapotranspiration and

$$
\begin{aligned}
& \mathrm{RF}=\text { rainfall } \\
& \mathrm{RO}=\text { runoff } \\
& \mathrm{P}=\text { percolation below root zone } \\
& \mathrm{S}=\text { change in soil water storage. }
\end{aligned}
$$

Infiltration was determined at four sites outside the plot in the forest area by the double-ring infiltrometer method. Maximum rainfall intensity was calculated from rainfall charis from a station about $5 \mathrm{~km}$ from the experimental site. Each daily chart from 1979 to 1986 was examined for the highest intensity during any 7.5 -minute period and this was divided by 7.5 10 give the intensity per minute. Root simples were obtained by excavating $10 \times 10 \times 10 \mathrm{~cm}$ of soil at each depth, and separating the roots by washing in water. Root length was determined by the method described by Newman (1966). The experimental plot was set up in December 1995. and data collection was begun in January 1996.

\section{Results and discussion}

\section{Site characteristics}

The experimental site is in a natural forest of about 50 ha. The canopy cover of was estimated to be about $90 \%$. The soil surface was covered with forest litter about $1-2 \mathrm{~cm}$ thick. The soil is a reddish-brown latasol. Weathering bedrock was found at about $160 \mathrm{~cm}$ below the surface. The slope is about $5 \%$. During the experimental period no water table was seen within $3 \mathrm{~m}$ of the surface in a well $50 \mathrm{~m}$ away, outside the forest. on the same contour. According to the Agro-ecological map of Sri Lanka (Land Use Division, 1979) the site falls in the mid-country intermediate zone.

\section{Rainfall and runoff}

There was $939 \mathrm{~mm}$ of rain during the nine months of observation in 1996. The monthly distribution in $\mathrm{mm}$ is given below:

$\begin{array}{cccccccccc}\text { Jan } & \text { Feb } & \text { Mar } & \text { Apr } & \text { May } & \text { Jun } & \text { Jul } & \text { Aug } & \text { Sep } & \text { Oct } \\ 172 & 29 & 14 & 237 & 0 & 91 & 26 & 28 & 105 & 237\end{array}$

The above distribution is about normal for this region. Eighty percent of the rainfall was received in 4 months. It was observed that there was no surface nunoff, even during the high rainfall months such as January, April, September and October.

\section{4}


Soil moisture storage

Fig. 3 shows the variation in the moisture content at different depths, in response to rainfall during the observation period. The variability of moisture content with time is greater in the surface layer than in the lower layers, which.shows that the response of the upper layers in receiving water from rainfall is quicker. Similarly, water losses from these layers also seem to be quicker (Fig. 4). The decper layers respond slowly, and with some time lag, to rainfall erents (Fig. 3). Even during wet months the soil moisture content at depths from 30 to 120 $\mathrm{cm}$ did not apploach field capacity (FC). However, during these months. moisture contents at the 15 and $150 \mathrm{~cm}$ depths remained closer to $\mathrm{FC}$. During the driest months (August and September) the moisture content at all depths except $150 \mathrm{~cm}$ fell below the permanent wilting point (PWP) and at $150 \mathrm{~cm}$ it remained close to the PWP. The soil moisture data presented in Fig. 3 indicate that March, July, and August were very critical months for survival of plants on this site, because of the shortage of water.

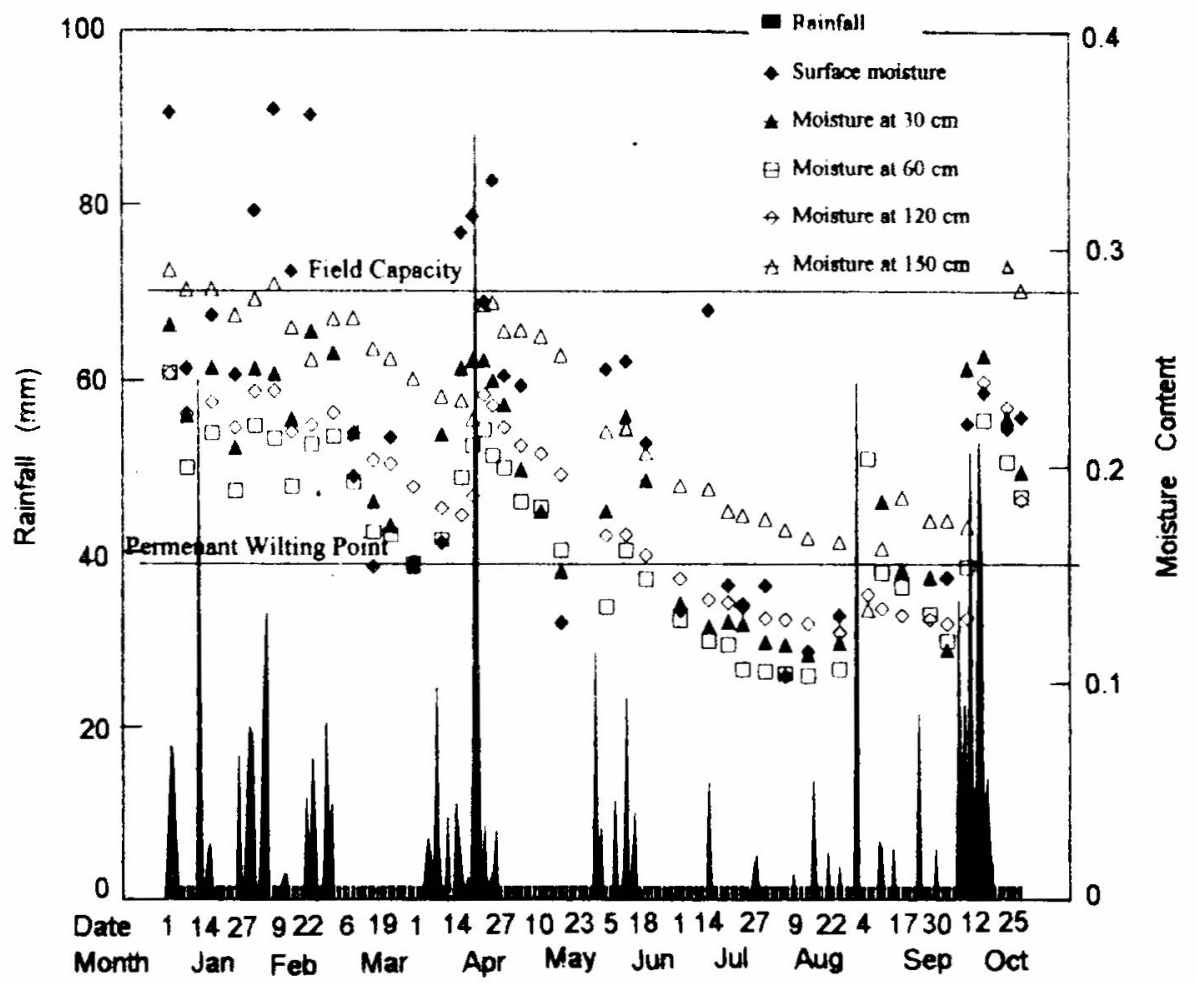

Figure 3: Variation of soil moisture in surface, $30 \mathrm{~cm}, 60 \mathrm{~cm}, 120 \mathrm{~cm}, 150 \mathrm{~cm}$ layers over the time in response to rainfall

Fig. 4 shows the soil-water extraction pattern during a dry period. Most of the water is extracted from the soil layers less than $90 \mathrm{~cm}$ deep. The same trend was noted in other dry 
Annual Forestry Symposium, 1996

periods. It is due to the fact that most of the roots are found in these layers. From one observation the root distribution in different layers was:

\begin{tabular}{ccc}
\hline Depth $(\mathbf{c m})$ & $\begin{array}{c}\text { Root length density } \\
\left(\mathbf{c m} / \mathbf{1 0 0 0} \mathbf{c m}^{\mathbf{3}} \mathbf{s o i l}\right)\end{array}$ & Percntage of total \\
\hline $0-15$ & 1402 & 42.2 \\
$15-30$ & 460 & 14.8 \\
$30-45$ & 724 & 21.8 \\
$45-60$ & 244 & 7.3 \\
$60-75$ & 216 & 6.5 \\
$75-90$ & 95 & 2.9 \\
$90-105$ & 93 & 2.8 \\
$105-120$ & 88 & 2.6 \\
\hline
\end{tabular}

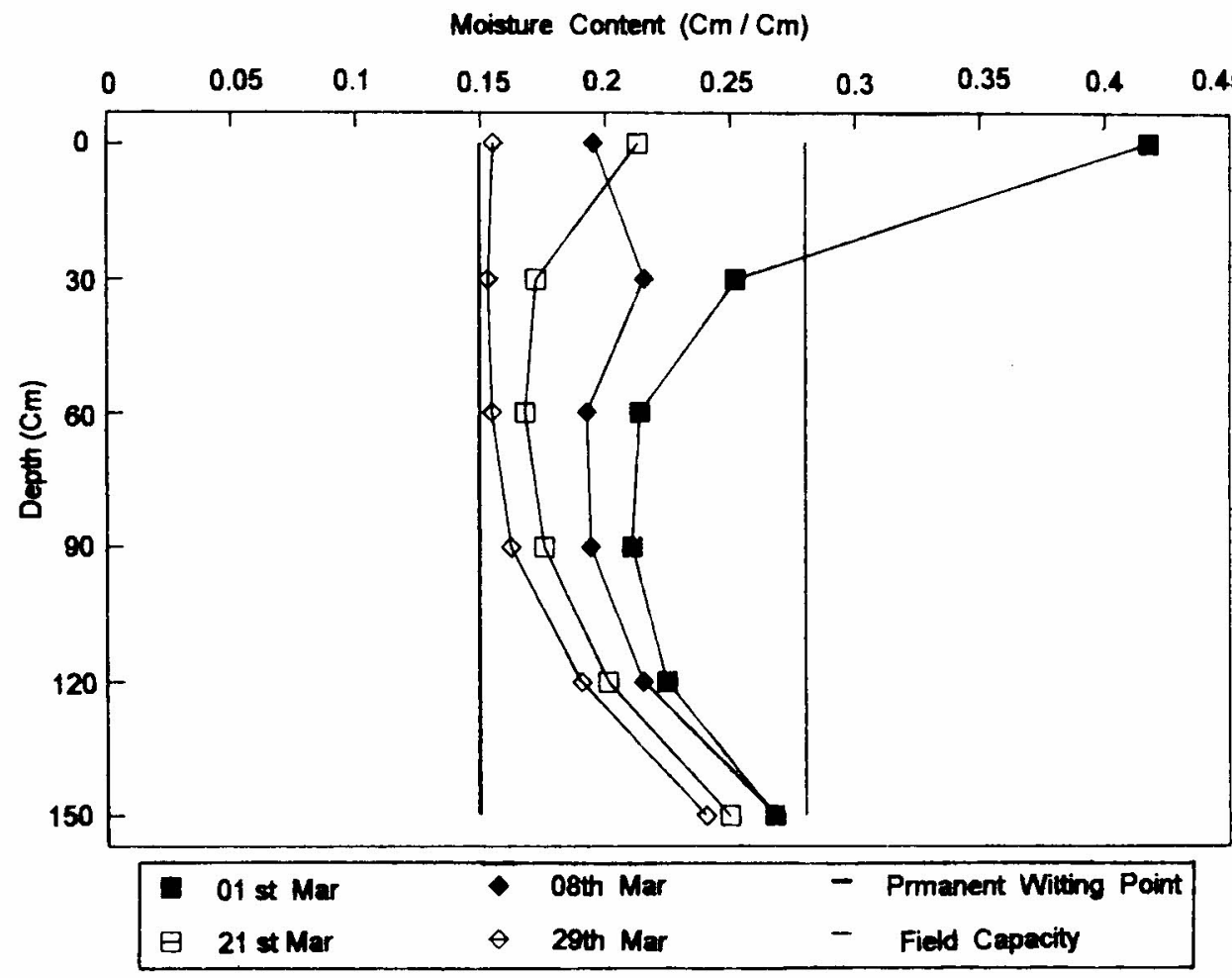

Figure 4: Depletion of soil moisture storage during a drying cycle in March 1996 
Nayakekorala and Madduma Bandara

Nearly $95 \%$ of the roots are in the top $90 \mathrm{~cm}$, and $42 \%$ in the top $15 \mathrm{~cm}$. These upper layers, intensively explored by roots, dry out very quickly. Fig. 4 shows that during drying cycles the soil layers down to $90 \mathrm{~cm}$ dried out to the PWP. During these dry periods the plants may be drawing water from the layers below $90 \mathrm{~cm}$.

Fig. 5 shows how soil moisture storage is replenished during a wetting cycle after the end of a dry period. Filling starts in the top soil layers and moves down, depending on rainfall. Filling of soil layers below $90 \mathrm{~cm}$ does not take place until surface soil layers are filled up close to FC.

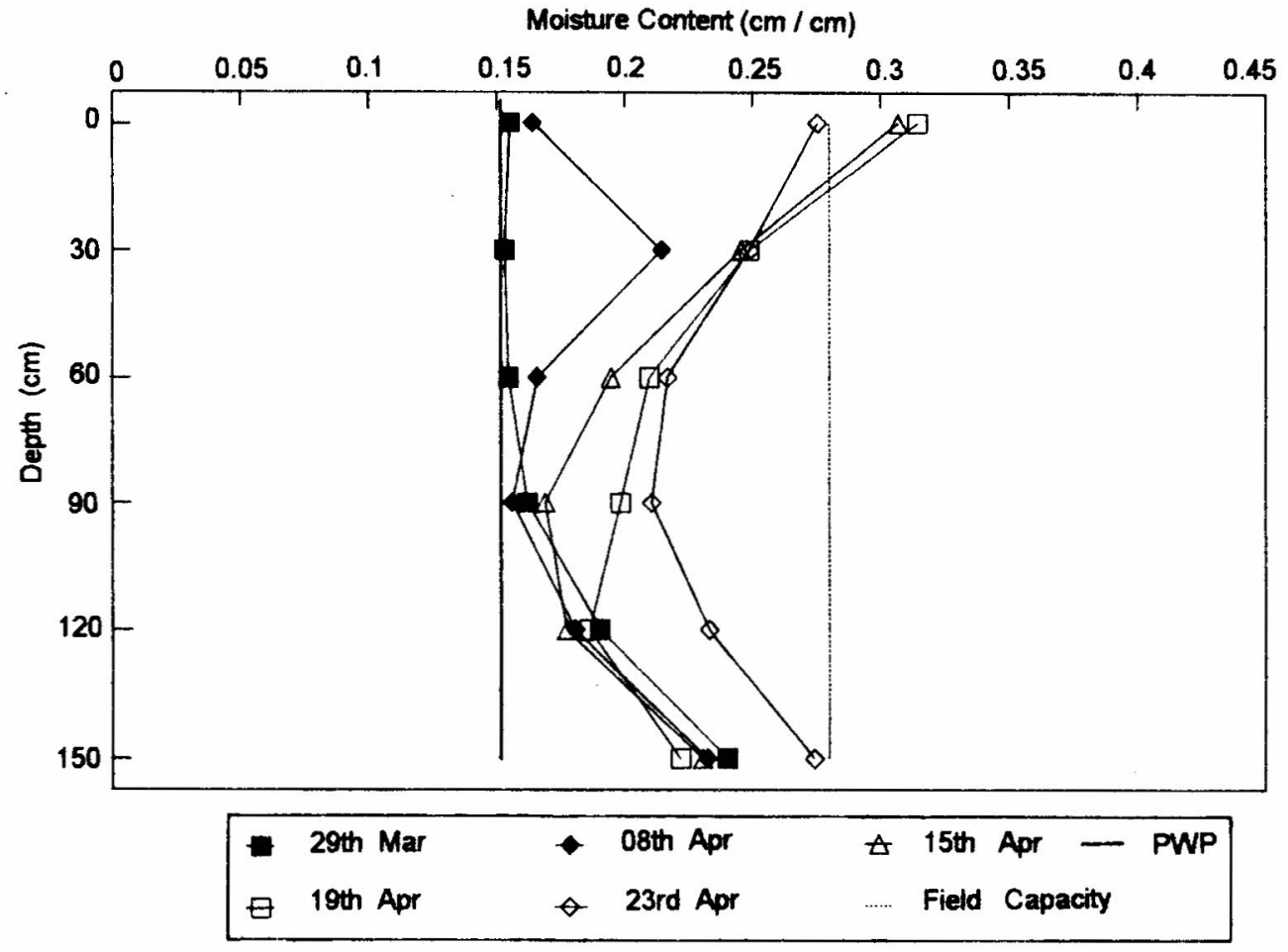

Figure 5: Filling of soil moisture storage during a wetting cycle in March 1996

\section{Rainfall in relation to soil moisture deficit}

For the purposes of this discussion, soil moisture deficit (SMD) is defined as the difference between total water storage in the profile (to $150 \mathrm{~cm}$ ) at FC and the observed storage in the profile; the profile at FC holds $462 \mathrm{~mm}$ of water. Table 1 shows the SMD on different dates, and the cumulative rainfall from one observation date to the next. The data show that there was an SMD at all of these dates. It was as little as $6 \%$ of the total storage in January (at the end of the main rainy season) and gradually increased up to mid-April. With the April rains the deficit decreased, but it increased again in the following dry period. During the driest 
Annual Forestry Symposium, 1996

months it rose $1050 \%$ of the total storage. A comparison between the SMD on a particular date and the cumulative rainfall until the next observation date will give an idea of the fate of that rainfall. If the rainfall exceeds the deficit there is a chance for overland flow or percolation to occur. Except on two occasions the rainfall was less than the deficit. indicating hat it was possible for all of the rainfall to be absorbed into the profile.

Table 1: Moisture deficit in the profile and cumulative rainfall between observation dates

\begin{tabular}{|c|c|c|c|}
\hline Date & Deficit (mm) & $\%$ & Cumulative rainfall (nm) \\
\hline 0.3 .01 .96 & 26 & 5.6 & 39) \\
\hline $09.01 . \% 6$ & 87 & 18.8 & 75 \\
\hline 18.01 .96 & 66 & 14.3 & 0 \\
\hline 26.01 .96 & 103 & 22.3 & 70 \\
\hline 02.02 .96 & 57 & 12.3 & 67 \\
\hline 09.02 .96 & 52 & 11.3 & 08 \\
\hline 15.02 .96 & 92 & 19.9 & 12 \\
\hline 01.03 .96 & 48 & 10.4 & 0 \\
\hline 08.03 .96 & 107 & 23.2 & 0 \\
\hline 15.03 .96 & 143 & 30.9 & 2 \\
\hline 21.03 .96 & 140 & 30.3 & 0 \\
\hline 29.03 .96 & 169 & 36.6 & 49 \\
\hline 08.04 .96 & 153 & 33.1 & 28 \\
\hline 15.04 .96 & 111 & 24.0 & 06 \\
\hline 19.04 .96 & 95 & 20.6 & 132 \\
\hline 23.04 .96 & 66 & 14.3 & 11 \\
\hline 26.04 .96 & 68 & 14.7 & II \\
\hline 30.04 .96 & 95 & 20.6 & 0 \\
\hline 06.05 .96 & 115 & 24.9 & 0 \\
\hline 13.05 .96 & 161 & 34.8 & 0 \\
\hline 20.05 .96 & 166 & 35.9 & 37 \\
\hline 05.06 .96 & 173 & 37.4 & 6 \\
\hline 12.06 .96 & 150 & 32.5 & 38.3 \\
\hline 19.06 .96 & 176 & 38.1 & 0 \\
\hline 01.07 .96 & 223 & 48.3 & 14 \\
\hline 11.07 .96 & 211 & 45.7 & 16 \\
\hline 18.07 .96 & 236 & 51.1 & 0 \\
\hline 2.3 .07 .96 & 241 & 52.2 & 10 \\
\hline 31.07 .96 & 248 & 53.7 & 0 \\
\hline 07.08 .96 & 256 & 55.4 & 3 \\
\hline 15.08 .96 & 259 & 56.1 & 21 \\
\hline 26.08 .96 & 257 & 55.6 & 64 \\
\hline 05.09 .96 & 272 & 58.9 & 07 \\
\hline 10.09 .96 & 233 & 50.4 & 12 \\
\hline 17.09 .96 & 241 & 52.2 & 22 \\
\hline 27.09 .96 & 249 & 53.9 & - \\
\hline
\end{tabular}




\section{Infitration}

Fig. 6 shows infiltration rates at the four sites as a function of time. They are highly variable among the sites. The basic infiltration rates range from 2.4 to $8.5 \mathrm{~mm} /$ minute, with a mean value of 5.0. On each site the basic rate was reached in about 2 hours.

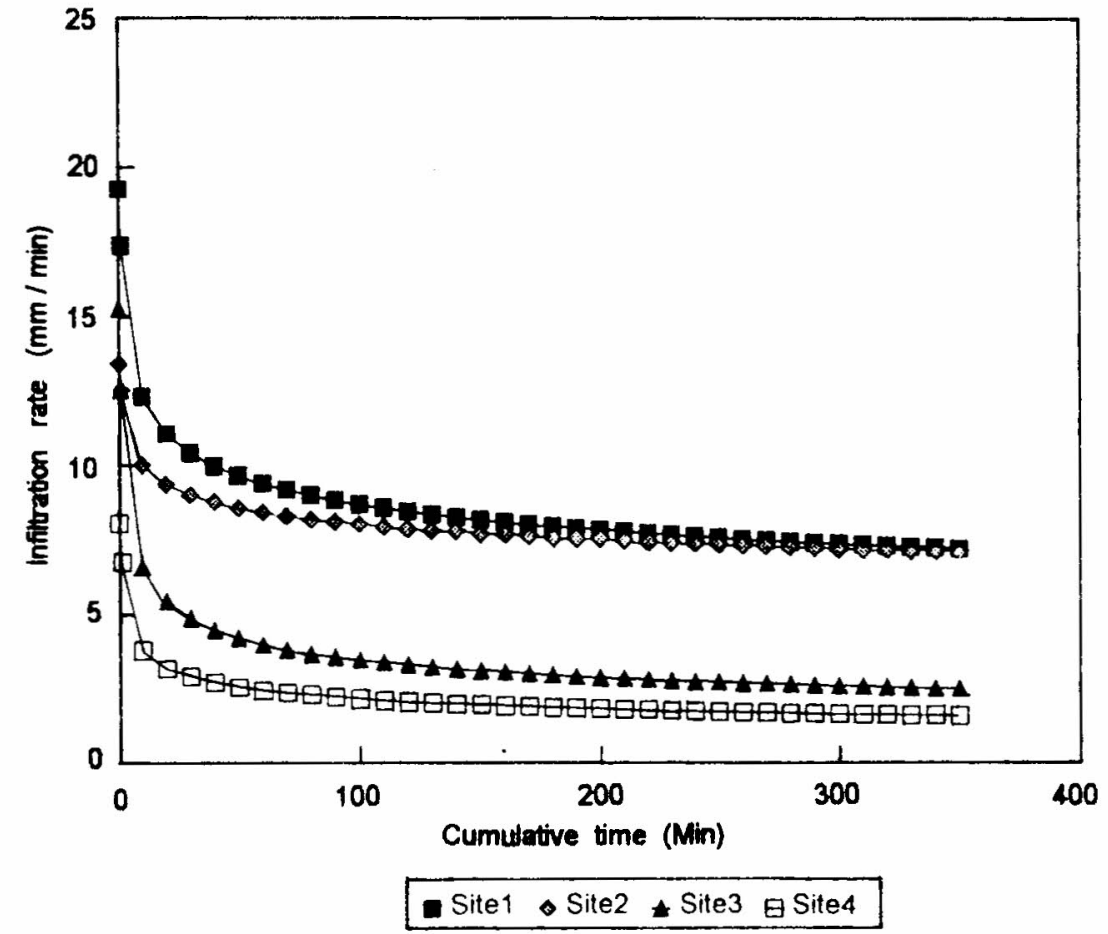

Figure 6: Infiltration rate as a function of time at 4 site in the experimental area

In watershed management, infiltration rates are important in relation to the possible occurrence of overland runoff. If the rainfall intensities are greater than the basic infiltration rates, then overland runoff can take place. Fig. 7 shows the frequency distribution of maximum rainfall intensity at a station $5 \mathrm{~km}$ away. About $90 \%$ of the rainstorms had maximum intensities of $<1 \mathrm{~mm} /$ minute. The minimum basic infiltration rate was 2.4 $\mathrm{mm} /$ minute, so it was well above maximum rainfall intensity. The comparison of basic infiltration rates and maximum rainfall intensity suggest that the chances overland runoff occurring at this site are small.

\section{Water loss by vegetation}

In the water-balance equation, the unknown components were ET and DP. It was planned to estimate DP, but the data on hydraulic conductivity and diffusivity were not collected. However, for the periods when DP could be considered negligible (on the basis of soil- 
moisture distribution) water loss was calculated with $\mathrm{DP}=0$. The results are given in Table 2.

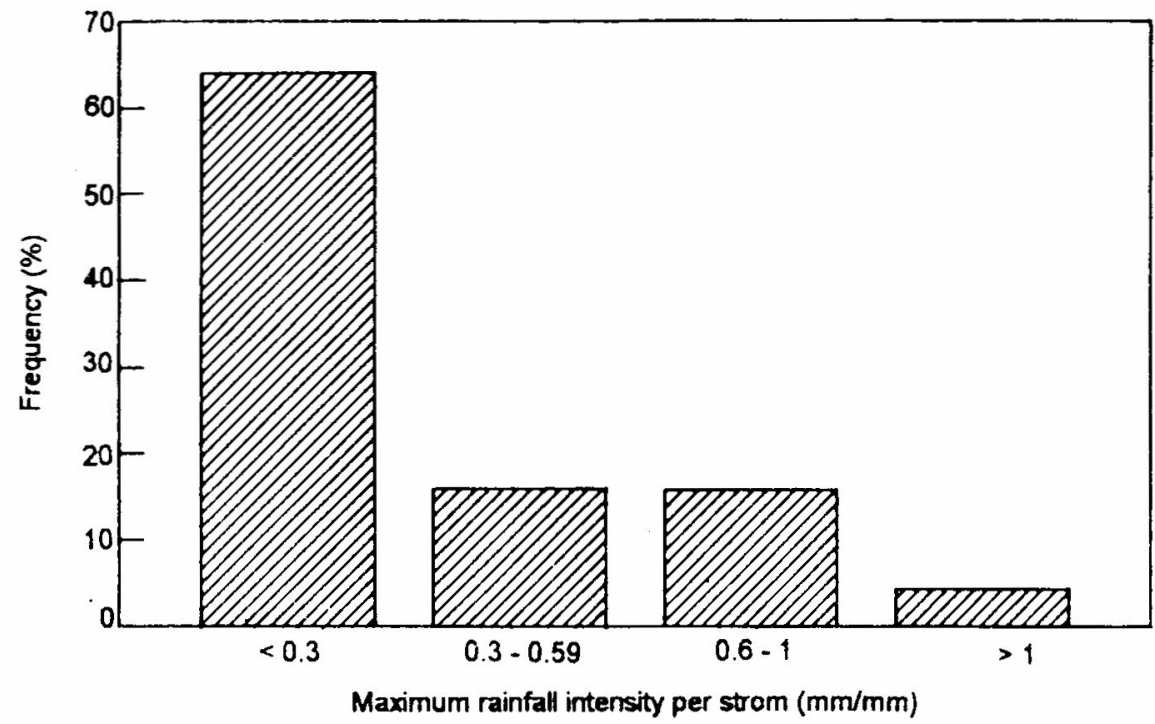

Figure 7: Frequency distribution of maximum intensity per rainstorm at Hapuwala, Hanguranketha

Table 2: Water use by forest vegetation from April to September 1996

\begin{tabular}{ccccc}
\hline Period & No. of days & $\mathrm{RF}^{1}(\mathrm{~mm})$ & $\begin{array}{c}\text { Total water in the } \\
\text { profile }(\mathrm{mm})^{2}\end{array}$ & $\begin{array}{c}\mathrm{ET} \\
(\mathrm{mm} / \text { day })\end{array}$ \\
\hline $30.4 .95-06.5 .96$ & 6 & 0 & 367 & 3.3 \\
$06.5 .96-12.5 .96$ & 6 & 0 & 346 & 3.6 \\
$12.5 .96-20.5 .96$ & 8 & 0 & & ND \\
$20.5 .96-05.6 .96$ & 16 & 36.7 & 295 & 2.7 \\
$05.6 .96-19.6 .96$ & 14 & 38.3 & 289 & 2.9 \\
$19.6 .96-01.7 .96$ & 12 & 0 & 286 & 3.9 \\
$01.7 .96-18.7 .96$ & 17 & 15.8 & 239 & 1.7 \\
$18.7 .96-31.7 .96$ & 13 & 10.2 & 226 & 1.7 \\
$31.7 .96-17.8 .96$ & 7 & 0 & 214 & 1.1 \\
$07.8 .96-15.8 .96$ & 8 & 3 & 206 & 0.75 \\
$15.8 .96-26.8 .96$ & 11 & 21.3 & 203 & 1.7 \\
$26.8 .96-10.9 .96$ & 15 & 63.7 & & NI) \\
$10.9 .96-17.9 .96$ & 7 & 11.7 & 217 & 4.1 \\
$179.96-27.9 .96$ & 10 & 21.5 & 246 & 2.8 \\
\hline
\end{tabular}


$\mathrm{ND}=$ not determined. ${ }^{1}$ Rainfall during two observation dates. ${ }^{2}$ Total water on the day of observation.

The data show that the water loss by vegetation (ET plus interception) is very low in this forest during the dry period. This low water loss can be attributed mainly to the low availability of water in the soil profile. The water loss by forest vegetation reported here compares closely with that reported by Munasinghe \& Somasiri (1992) for the dry zone. The losses decreased gradually up to August. and then increased with increasing rainfall.

On this site the soil profile was shallow: decomposing bed rock was found at about $160 \mathrm{~cm}$. Soil moisture change was therefore monitored only to $150 \mathrm{~cm}$. Root sampling was also resiricted to this depth. However. roots might have penetrated further down, through cracks of the bedrock and extracted water from there during dry periods when the soil profile remained dry. This study may therefore have under-cstimated the water loss by the vegetation.

\section{Conclusions}

Rainfalt of $939 \mathrm{~mm}$ during the 9-month observation period did not resulted in any overland renoil from the experimental site (observations showed no sign of overland runoff from the main calchment eithor). The soil moisture down to the impervious layer $(150 \mathrm{~cm})$ showed an SMD during most of the period. The basic infiltration rate ranged from 2.4 ic 8.5 mm/mimute, whth a mean value of 5 . The maximum rainfall intensities in the area were found to be ver much less $(<1 \mathrm{~mm} /$ minute) than the basic infiltration rates. The rainfall distribution and soil moisture conditions of the profile suggest that there was very little chance for any considerable deep percolation to have occurred during the experimental period. The results of this research indicate that much of the rainfall was used by the vegetation during the period under study and were not available for overland runoff or percolation. The data on water loss by vegetation reported here may not be conclusive because there is the possibility that roots may have penetrated further down and extracted water from the deeper lavers. These findings have to be compared with those from other similar locations before any generalized conclusions are reached.

\section{Acknowledgements}

This research was partly funded by CARP Contract Research Project 12/215/177. Support given by Messrs K.M. Kanunarathna and G.B.S.Samaranayaka in data collection, Mr H.K. Kadupitiya in data analysis, and Miss Nectha Jayakody and Miss N. Rankothge in word processing is very much appreciated.

\section{References}

Bosch. J.M. and Hewllet. J.D. (1982). A review of catchment experiments to determine effects of vegetation changes on water yield and evapotranspiration. Hydrology 55, $3-23$. 
Annual Forestry Symposium, 1996

Gilmour, D.A. (1977). Effect of rain forest logging and clearing on water vield and quality in a high rainfall zone of northeast Queensland. Proceedings, Hydrology Symposium, Institute of Engineering, Brisbane. Pp. 156-60.

Land Use Division (1979). Agro-ecological map of Sri Lanka. Department of Agriculture. University of Peradeniya.

Madduma Bandara. C.M. (1992). Trees and water: some unresolved. issues. Proceedings, Symposium on Multi-Purpose Tree Species in Sri Lanka. H.P.M.Gunasena (Ed). Faculty of Agriculture, University of Peradeniya.

Munasinghe, M.A.K. and Somasiri, S. (1992). Moisture consumption by dominant vegetation types in the dry zone of Sri Lanka and its influence on the hydrologic cycle. Tropical Agriculturist 148.

Newman, E.I. (1966). A method of estimating total length of roots in a sample. Journal of Applied Ecology 3, $139-45$. 